\title{
Características físico-químicas e nutricionais de pimentão produzido em campo e hidroponia
}

\author{
Physico-chemical and nutritional characteristics of bell pepper produced \\ in the field and through a hydroponic production system
}

Maria Madalena RINALDI ${ }^{1 \star}$, Delvio SANDRI², Michelle de Oliveira RIBEIRO ${ }^{3}$, Adriana Garcia do AMARAL ${ }^{4}$

\begin{abstract}
Resumo
O trabalho objetivou avaliar as características físicas, químicas e a composição centesimal de cultivares de pimentão armazenadas em condição ambiente natural (temperatura de $21 \pm 2{ }^{\circ} \mathrm{C}$ e umidade relativa do ar de $70 \pm 5 \%$ ). O experimento foi realizado em delineamento experimental inteiramente casualizado, com quatro tipos de pimentão (Paloma e Impacto com cultivares produzidas hidroponicamente; e Paloma e Magali produzidas em campo) e seis períodos de análise, com três repetições. As cultivares Paloma produzida em campo e Impacto produzida em hidroponia apresentaram a maior massa. O maior teor de umidade e o menor teor de fibra bruta foram obtidos na cultivar Paloma, e o maior teor de proteínas e carboidratos na cultivar Magali. Os sólidos solúveis foram mais elevados no tratamento Magali campo. A umidade não foi influenciada pelos tratamentos e armazenamento. Aos 12 dias de armazenamento todos os tratamentos apresentaram valores elevados de vitamina C, sendo maior no Impacto hidropônico e menor no Magali campo. A perda de massa fresca atingiu $14,11 \%$ aos 12 dias de armazenamento, sendo considerado o período limite para o armazenamento do pimentão. A cultivar Paloma e a Impacto podem ser recomendadas para o cultivo.

Palavras-chave: Capsicum annuum; composição centesimal; armazenamento; vida útil.
\end{abstract}

\begin{abstract}
The objective of this work was to evaluate the physicochemical characteristics and proximate composition of bell pepper cultivars stored in natural ambient conditions (temperature of $21 \pm 2{ }^{\circ} \mathrm{C}$ and relative humidity of $70 \pm 5 \%$ ). The experiment was carried out using a completely randomized design, with four types of bell peppers (Paloma and Impacto produced through a hydroponic production system; Paloma and Magali produced in the field) and six analysis periods, with three repetitions. The cultivars Paloma produced in the field and hydroponic Impacto presented the greatest mass. The highest moisture and lowest crude fiber contents were obtained for Paloma cultivar, and the highest protein and carbohydrate contents, for Magali cultivar. Soluble solids were higher in Magali produced in the field. Moisture was not influenced by the treatments (field or hydroponic) and storage. During the 12 days of storage, all treatments presented high values of vitamin C, being higher in hydroponic Impacto and lower in Magali from the field. Mass loss reached $14.11 \%$ at 12 days of storage, which was considered the limiting period for bell pepper storage. Paloma and Impacto cultivars can be recommended for cultivation.
\end{abstract}

Keywords: Capsicum annuum L.; centesimal composition; storage; shelf life.

\section{Introdução}

O pimentão (Capsicum annuum L.) está entre as dez hortaliças mais importantes cultivadas no Brasil, estando difundido principalmente nas regiões sudeste e centro-oeste (BLAT-MARCHIZELI; YAÑEZ; COSTA, 2003). No centrooeste, o maior produtor é o Estado de Goiás, tendo comercializado 4347 toneladas em 2005, sendo 93,12\% produzido no próprio estado, onde os municípios de Anápolis, Turvânia, Ouro Verde, Leopoldo de Bulhões, Goiânia, Teresópolis, Piracanjuba e Silvânia são os principais produtores (CEASA/GOIÁS, 2007). A produção de pimentão é predominantemente realizada em condições de campo, no entanto, nos últimos anos o plantio em ambiente protegido também tem sido realizado, sendo uma das culturas que melhor tem se adaptado a este sistema, possibilitando vantagens como a produção em períodos de entressafra, redução dos efeitos de fatores como ventos, excesso ou escassez de chuvas, doenças, entre outros. No entanto, novas cultivares de pimentão foram desenvolvidas, sendo necessários mais estudos para analisar sua adaptação ao cultivo em campo e em ambiente protegido, considerando conjuntamente a eficiência do uso da água, de nutrientes, fatores edafoclimáticos e técnicas de cultivo.

Com o desenvolvimento da agricultura nas últimas décadas e com a necessidade de aumentar a produtividade e a qualidade dos produtos, o agricultor necessitou tecnificar cada vez mais, adequando seu produto e seus meios de produção à atual demanda. Este aspecto se acentua quando se trata de horticultura, pois a maioria dos produtores possuem pequena área para cul-

\footnotetext{
Recebido para publicação em 26/2/2007

Aceito para publicação em 29/8/2007 (002320)

Faculdade de Química Industrial e Engenharia Agrícola, Universidade Estadual de Goiás - UEG, BR 153, Km 98, CP 459, CEP 75110-390, Anápolis - GO,

E-mail:rinaldi@ueg.br

2 Engenharia Agrícola, Faculdade de Engenharia Agrícola, Universidade Estadual de Goiás - UEG, E-mail: sandri@ueg.br

${ }^{3}$ Química Industrial, Universidade Estadual de Goiás - UEG, E-mail: michelle.oliribeiro@gmail.com

${ }^{4}$ Engenharia Agrícola, Universidade Estadual de Goiás - UEG, E-mail: driaga@gmail.com

${ }^{*}$ A quem a correspondência deve ser enviada
} 
tivo, de onde buscam retirar o máximo de rendimento de sua propriedade. Neste sentido, o cultivo sem solo é uma técnica racional que visa a otimização no uso da água, do espaço físico, do tempo, dos nutrientes e da mão-de-obra (VILLELA JÚNIOR; ARAÚJO; FACTOR, 2003).

Segundo Rocha et al. (2006), muitas das tecnologias desenvolvidas para a cultura do pimentão estão voltadas para a melhoria da produtividade e da aparência dos frutos, sem considerar aspectos como sabor, valor nutricional e resíduos tóxicos remanescentes, resultando em escassez de informações na literatura e dificultando a análise dos resultados sobre a composição e as características físico-químicas de frutos de pimentão. De acordo com Reifschneider (2000), os frutos de pimentão possuem elevados teores de vitaminas $\mathrm{A}, \mathrm{C}$ e E, sais minerais, cálcio, sódio, fósforo e ferro. Possuem ainda, cerca de 48 calorias por $100 \mathrm{~g}$ de produto.

Para Chitarra (1998), a qualidade de frutos e hortaliças é caracterizada com base em atributos como aparência, sabor, textura e valor nutritivo. Esta caracterização, segundo Rocha et al. (2006), é importante, devendo ser observadas as variáveis necessárias para a melhoria da comercialização no mercado interno e externo, bem como para o desenvolvimento de técnicas de armazenamento e de manejo pós-colheita, sendo de fundamental importância a avaliação do efeito de práticas de manejo sobre a produtividade, a qualidade química e física do produto e a longevidade durante o processo de comercialização.

O trabalho objetivou avaliar as características físicoquímicas e nutricionais das cultivares de pimentão Paloma e Impacto produzidas hidroponicamente, e Paloma e Magali produzidas em campo e armazenadas sob condições ambiente pelo período de 12 dias.

\section{Material e métodos}

O trabalho foi realizado com cultivares de pimentão Paloma, Impacto e Magali, produzidas na safra de 2006 e colhidas em junho do mesmo ano, no município de Anápolis-GO. O clima na região é considerado mesotérmico e úmido, classificado como provável clima tropical de altitude, com temperatura média anual de $22^{\circ} \mathrm{C}$ e precipitação de $1450 \mathrm{~mm}$. Ocorrem baixas temperaturas em junho e julho, com média mínima de $10^{\circ} \mathrm{C}$. A cultivar Paloma foi produzida em dois sistemas de cultivo: campo e hidroponia. A cultivar Impacto foi produzida apenas em hidroponia e a Magali somente em campo. As cultivares Paloma e Impacto foram lançadas recentemente no mercado de sementes de hortaliças, e a cultivar Magali é a mais produzida e comercializada da região. $\mathrm{O}$ experimento consistiu em 4 tratamentos: Paloma hidropônica; Paloma campo; Impacto hidropônica e Magali campo.

O cultivo em sistema hidropônico foi realizado na Fazenda Formiga ( $16^{\circ} 19^{\prime} 36^{\prime \prime}$ Sul e $48^{\circ} 57^{\prime} 10^{\prime \prime}$ Oeste e altitude de $1017 \mathrm{~m}$ ) em casa de vegetação com formato de túnel alto $(14,0 \mathrm{~m}$ de largura e 60,0 m de comprimento), fechamento lateral e frontal com tela tipo clarite de polietileno transparente (50\%) até a altura do pé direito $(3,0 \mathrm{~m})$, com cobertura de polietileno de baixa densidade transparente ( $150 \mu \mathrm{m}$ de espessura), contendo difusor de luz e antivírus aditivado com antiultravioleta (UV).
Foram construídos doze leitos de cultivo com $0,2 \mathrm{~m}$ de largura e $0,30 \mathrm{~m}$ de profundidade, impermeabilizados com plástico e preenchidos com areia lavada, apresentando módulo de finura médio de 2,21 mm e dimensão máxima característica de $6,3 \mathrm{~mm}$, com valores iniciais de condutividade elétrica de $0,1 \mathrm{dS} \mathrm{m}^{-1}$. A solução nutritiva foi preparada conforme Castellane e Araujo (1995) e aplicada por sistema de gotejamento.

O cultivo em campo foi realizado em uma lavoura comercial com espaçamento de $1,0 \mathrm{~m}$ entre linhas e $0,40 \mathrm{~m}$ entre plantas, utilizando-se o sistema de irrigação por sulco, sendo o turno de rega definido conforme a necessidade hídrica da cultura.

A colheita foi realizada de forma manual aos 140 dias após o transplantio para os pimentões cultivados em hidroponia e 135 dias para os pimentões produzidos em campo. Os frutos de pimentão foram colhidos no ponto de maturação comercial, sendo o critério de determinação do ponto de colheita realizado de forma visual pelos produtores. Após a colheita, os frutos foram selecionados descartando-se os que apresentavam doenças, imperfeições e desuniformidade de maturação. Em seguida, foram transportados em caixas de papelão sem refrigeração para o Laboratório de Tecnologia de Fermentações e Enzimologia da Unidade Universitária de Ciências Exatas e Tecnológicas UnUCET da Universidade Estadual de Goiás - UEG, Anápolis, $\mathrm{GO}$, onde foram mantidos em condição ambiente natural $\left(21 \pm 2{ }^{\circ} \mathrm{C}\right.$ e umidade relativa do ar de $\left.70 \pm 5 \%\right)$, no período de 26 de junho a 7 de julho de 2006.

Logo após a colheita foram determinadas as características físicas (massa, comprimento e diâmetro) e a composição centesimal (umidade, lipídios, proteínas, fibra bruta, cinzas e carboidratos). Aos 0, 3, 5, 8, 10 e 12 dias de armazenamento analisou-se o pH, acidez titulável, sólidos solúveis, vitamina $\mathrm{C}$ e umidade. A perda de massa fresca foi determinada aos 3, 5, 8, 10 e 12 dias de armazenamento. A massa e a perda de massa fresca foram determinadas utilizando-se uma balança modelo AL 500C, com precisão de 0,001 g. Para o comprimento e diâmetro utilizou-se um paquímetro digital com precisão de $0,01 \mathrm{~mm}$. As demais análises foram realizadas conforme a metodologia descrita pelo Instituto Adolfo Lutz (1985). Devido às condições experimentais, realizou-se a análise de fibra bruta ao invés da determinação de fibra alimentar total, conforme exigências da legislação brasileira para a rotulagem de alimentos.

O delineamento experimental foi o inteiramente casualizado, em esquema fatorial $4 \times 6$ (quatro tipos de pimentão e seis períodos de análise), com três repetições, em que cada repetição consistiu em três frutos de pimentão, com exceção das análises de massa, comprimento e diâmetro, que foram realizadas em 20 pimentões por tratamento. Após a análise de variância, as médias foram comparadas pelo teste de Tukey a $1 \%$ de probabilidade, com o auxílio do software Estat (1994).

\section{Resultados e discussão}

Os frutos de pimentão das cultivares Paloma produzida em campo e Impacto produzida em hidroponia apresentaram a maior massa (Tabela 1). O maior comprimento foi obtido nos pimentões da cultivar Magali, produzidos em campo, sendo superior às cultivares Paloma e Impacto produzidas em 
hidroponia. A cultivar Magali apresentou o menor diâmetro. Rocha et al. (2006) observaram que a maior massa de frutos, o maior comprimento e o volume dos frutos foram obtidos pelo híbrido Magali R, quando avaliaram o efeito de pulverizações semanais com biofertilizante Agrobio, oxicloreto de cobre, sulfato de estreptomicina mais oxitetraciclina e, água como testemunha, para as cultivares de pimentão Magda, Cascadura Itaipu e o híbrido Magali R.

A umidade dos pimentões variou de 92,59 a 93,88\% (Tabela 2), sendo similar aos valores apresentados pelo Nepa (2004), que foi de $94,0 \%$ para o pimentão verde in natura (variedade não especificada). Os tratamentos Paloma hidropônico e Paloma campo apresentaram teor de umidade significativamente superior aos demais tratamentos. O menor teor de umidade foi apresentado pela cultivar Magali produzida em campo, sendo inferior ao obtido por Pilon et al. (2006), que obtiveram o valor médio de $94,16 \%$ de umidade em pimentão da cultivar Magali minimamente processado. O teor de lipídios não apresentou diferença significativa entre os tratamentos, com valores variando entre 0,11 e $0,14 \%$. No entanto, Pilon et al. (2006) obtiveram o valor de $0,08 \%$ de lipídios em pimentão da cultivar Magali minimamente processado. Esses resultados correspondem aos apresentados pelo Nepa (2004), que afirma que o pimentão verde in natura (variedade não especificada) apresenta apenas traços de lipídios em sua composição.

O teor de proteínas obtido foi inferior ao descrito pelo Nepa (2004), que é de 1\%. A cultivar Magali produzida em campo apresentou o maior valor de proteína, sendo inferior ao obtido por Pilon et al. (2006). O menor valor foi verificado na cultivar Impacto, produzida no sistema hidropônico. O menor valor de fibra bruta foi observado na Paloma produzida em campo, diferindo dos demais tratamentos, enquanto que o maior valor,

Tabela 1. Massa, comprimento e diâmetro de pimentões Paloma Hidropônico (PH), Paloma Campo (PC), Impacto Hidropônico (IH) e Magali Campo (MC).

\begin{tabular}{lrrrrr}
\hline \multirow{1}{*}{ Determinação } & \multicolumn{4}{c}{ Tratamentos } & \multirow{2}{*}{ CV (\%) } \\
\cline { 2 - 5 } & \multicolumn{1}{c}{ PH } & \multicolumn{1}{c}{ PC } & \multicolumn{1}{c}{ IH } & \multicolumn{1}{c}{ MC } & \\
\hline Massa (g) & $164,30^{\mathrm{B}}$ & $210,93^{\mathrm{A}}$ & $190,54^{\mathrm{A}}$ & $163,76^{\mathrm{B}}$ & 15,81 \\
Comprimento (cm) & $12,29^{\mathrm{C}}$ & $14,06^{\mathrm{AB}}$ & $12,93^{\mathrm{BC}}$ & $14,42^{\mathrm{A}}$ & 10,56 \\
Diâmetro (cm) & $6,79^{\mathrm{A}}$ & $6,99^{\mathrm{A}}$ & $6,85^{\mathrm{A}}$ & $5,91^{\mathrm{B}}$ & 6,65 \\
\hline
\end{tabular}

Médias seguidas por letras distintas na mesma linha diferem entre si a $1 \%$ pelo teste de Tukey.

Tabela 2. Valores médios da composição centesimal (\%) de pimentões Paloma Hidropônico (PH), Paloma Campo (PC), Impacto Hidropônico (IH) e Magali Campo (MC).

\begin{tabular}{lrrrrr}
\hline \multirow{2}{*}{ Determinação } & \multicolumn{4}{c}{ Tratamentos } & \multirow{2}{*}{ CV (\%) } \\
\cline { 2 - 4 } & \multicolumn{1}{c}{$\mathrm{PH}$} & \multicolumn{1}{c}{$\mathrm{PC}$} & \multicolumn{1}{c}{$\mathrm{IH}$} & \multicolumn{1}{c}{$\mathrm{MC}$} & \\
\hline Umidade & $93,85^{\mathrm{A}}$ & $93,88^{\mathrm{A}}$ & $93,28^{\mathrm{B}}$ & $92,59^{\mathrm{C}}$ & 8,15 \\
Lipídios & $0,12^{\mathrm{A}}$ & $0,11^{\mathrm{A}}$ & $0,11^{\mathrm{A}}$ & $0,14^{\mathrm{A}}$ & 12,56 \\
Proteína & $0,09^{\mathrm{B}}$ & $0,09^{\mathrm{B}}$ & $0,07^{\mathrm{C}}$ & $0,12^{\mathrm{A}}$ & 4,86 \\
Fibra bruta & $0,51^{\mathrm{A}}$ & $0,28^{\mathrm{B}}$ & $0,57^{\mathrm{A}}$ & $0,57^{\mathrm{A}}$ & 5,24 \\
Cinzas & $0,35^{\mathrm{A}}$ & $0,35^{\mathrm{A}}$ & $0,38^{\mathrm{A}}$ & $0,42^{\mathrm{A}}$ & 8,19 \\
Carboidratos & $5,06^{\mathrm{B}}$ & $5,26^{\mathrm{B}}$ & $5,57^{\mathrm{B}}$ & $6,14^{\mathrm{A}}$ & 2,07 \\
\hline
\end{tabular}

Médias seguidas por letras maiúsculas distintas na mesma linha diferem entre si a $1 \%$ pelo teste de Tukey. apesar de não diferir estatisticamente do tratamento Paloma hidropônico, foi obtido nos tratamentos Impacto hidropônico e Magali campo. Os valores de fibra bruta foram inferiores $(2,6 \%)$ aos de fibra alimentar total apresentado pelo Nepa (2004). O teor de cinzas foi similar aos indicados pelo Nepa (2004), com o menor valor na cultivar Paloma produzida em hidroponia e em campo, embora não diferindo estatisticamente dos demais tratamentos. A cultivar Magali produzida em campo apresentou os maiores valores de carboidratos $(6,14 \%)$, que de modo geral, para todas as cultivares foram superiores aos observados pelo Nepa (2004) para o pimentão verde in natura (5\%) e, por Carmo (2004) para o pimentão amarelo cultivar Zarco HS (5\%). O maior valor de carboidratos obtido nesse experimento pode ser justificado pelas características das variedades, ou a menor quantidade existente dos demais componentes da composição centesimal, já que o mesmo foi obtido por diferença (Nifext).

$\mathrm{O}$ pH variou entre 5,12 e 5,79, sendo os maiores valores observados no tratamento Magali campo, do primeiro ao quinto dia de armazenamento. Do oitavo ao décimo segundo dia, os maiores valores foram obtidos no tratamento Paloma hidropônico, porém, não diferindo significativamente dos demais tratamentos (Tabela 3). Rocha et al. (2006) obtiveram valores entre 5,51 e 5,90 nas cultivares Magda, Cascadura Itaipu e Magali R., situando-se na faixa de frutos não ácidos, conforme estabelecido por Gould (1974). Durante o armazenamento ocorreu redução significativa nos valores de $\mathrm{pH}$ somente nos tratamentos Impacto hidropônico e Magali campo. No primeiro dia de armazenamento o $\mathrm{pH}$ da cultivar Paloma produzida em hidroponia foi menor que o da Magali produzida em campo, enquanto que no terceiro dia diferiu também da cultivar Impacto, produzida em hidroponia. Os valores de $\mathrm{pH}$ obtidos situam-se na faixa citada por Cochran (1964), que afirma que o pH do pimentão atinge 6,52 no fruto verde imaturo e depois tende a diminuir com o amadurecimento, chegando a 5,02 no fruto maduro. Pilon et al. (2006) observaram que o pimentão da cultivar Magali minimamente processado apresentou $\mathrm{pH}$ maior no décimo quarto e vigésimo primeiro dia de armazenamento em relação ao primeiro e sétimo dia, com variação de 5,4 a 6,3 durante os 21 dias de armazenamento em temperatura de $1 \pm 1{ }^{\circ} \mathrm{C}$ em atmosfera modificada passiva, ativa e em vácuo.

O teor de acidez titulável variou entre $0,07 \mathrm{~g}$ de ácido málico $100 \mathrm{~g}^{-1}$ e $0,16 \mathrm{~g}$ de ácido málico $100 \mathrm{~g}^{-1}$ durante os 12 dias de armazenamento, com variação significativa somente entre os tratamentos Impacto hidropônico e Magali campo (Tabela 3). Os maiores teores de acidez titulável foram obtidos na cultivar Magali aos 10 e 12 dias de armazenamento, correspondendo aos menores valores de $\mathrm{pH}$ para esta variedade, sendo inferiores aos valores observados por Rocha et al. (2006), no quais os pimentões atingiram valores de 0,86 e $1,57 \%$ para a cultivar Cascadura Itaipu. Pilon et al. (2006) obtiveram acidez titulável de $0,05 \mathrm{mg}$ ácido cítrico $100 \mathrm{~g}^{-1}$ de pimentão da cultivar Magali minimamente processado, não havendo variação significativa durante o armazenamento por 21 dias, em temperatura de $1 \pm 1{ }^{\circ} \mathrm{C}$ em atmosfera modificada passiva, ativa e em vácuo. Pimentões da cultivar Ikeda mantidos por 8 dias em condição ambiente apresentaram valores médios de $0,12 \%$ de ácido cítrico (HOJO et al., 2007). Nos tratamentos Impacto hidropônico e Magali campo ocorreram aumento significativo na concen- 
tração de ácido málico em alguns períodos de análise. Esses resultados podem corresponder à variabilidade das amostras das diferentes variedades, ou de acordo com Antoniali et al. (2007), este comportamento pode ser justificado pelo fato de que, à medida que o fruto amadurece, aumentam as reações metabólicas, aumentando a concentração dos ácidos orgânicos envolvidos no ciclo de Krebs.

Os sólidos solúveis (Tabela 4) oscilaram entre 4,60 e $7,40^{\circ}$ Brix durante os 12 dias de armazenamento. O tratamento Paloma hidropônico apresentou menor valor de sólidos solúveis que os tratamentos Paloma e Magali produzidos em campo, no primeiro, quinto e décimo segundo dia de armazenamento. $\mathrm{O}$ maior valor de sólidos solúveis durante o armazenamento foi obtido no tratamento Magali campo, com exceção do terceiro dia, em que não diferiu do Paloma campo, e no oitavo dia, em que não ocorreu diferença significativa entre os valores de sólidos solúveis de todos os tratamentos. Rocha et al. (2006) observaram valores entre 6,01 e 7,0 ${ }^{\circ} \mathrm{Brix}$ para as cultivares Magda, Cascadura Itaipu e Magali R. Antonialli et al. (2007) obtiveram valores entre 5,76 e 7,93 ${ }^{\circ}$ Brix para o pimentão amarelo Zarco HS. Para Vicentini et al. (1999) o valor médio de sólidos solúveis foi de $6,62^{\circ} \mathrm{Brix}$ em pimentões da cultivar Valdor mantidos à temperatura entre 26 e $29^{\circ} \mathrm{C}$ e umidade relativa de 59,5 a 71,5\%, por 12 dias. De acordo com Grierson e Kader (1986), a princípio, quanto maior o teor de açúcares e de ácidos, melhor o sabor do fruto.

Os valores de vitamina $C$ variaram entre 73,64 mg de ácido ascórbico $100 \mathrm{~g}^{-1}$ de produto e 213,52 mg de ácido ascórbico $100 \mathrm{~g}^{-1}$ de produto, durante os 12 dias de armazenamento (Tabela 4). Durante o armazenamento ocorreu redução e aumento significativo somente para o tratamento Paloma hidropônico e Impacto hidropônico. No entanto, esses dois tratamentos sempre apresentaram valores superiores de vitamina $C$ quando comparados ao tratamento Magali campo, que apresentou menor valor que os demais tratamentos, durante todo o período de armazenamento. De maneira geral, os pimentões da variedade Paloma produzidos em hidroponia apresentaram maior valor de vitamina $C$ durante o armazenamento. Com exceção do tratamento Magali campo, durante os 12 dias de armazenamento, os demais tratamentos apresentaram valores de vitamina $\mathrm{C}$ superiores ao valor estabelecido (100 mg de ácido ascórbico $100 \mathrm{~g}^{-1}$ ) pelo Nepa (2004) para pimentão verde (variedade não especificada). De maneira geral, o fruto de pimentão é um produto bastante rico em vitamina C (FRANCO, 1999). Os valores observados neste trabalho foram inferiores aos obtidos por Pilon et al. (2006) para a cultivar Magali minimamente processada, com leve diminuição da vitamina C, passando de $138,85 \mathrm{mg}$ de ácido ascórbico $100 \mathrm{~g}^{-1}$ no primeiro dia de armazenamento, para 120,15 mg de ácido ascórbico $100 \mathrm{~g}^{-1}$ aos 21 dias de armazenamento. De acordo com Cheftel et al. (1983), a oxidação da vitamina C é acelerada pela ação das enzimas ascorbato oxidase ou peroxidase durante o armazenamento de frutos e hortaliças. A vitamina C é a mais instável das vitaminas por ser sensível aos agentes físico-químicos como luz, oxigênio e calor, sendo que altas temperaturas e longos períodos de estocagem aceleram a perda desta vitamina. De acordo com Lee e Kader (2000), o teor de vitamina $\mathrm{C}$ em frutas e hortaliças pode ser influenciado por vários fatores, como as condições climáticas na pré-colheita, práticas culturais, ponto de maturação, métodos de colheita $\mathrm{e}$ tratamento pós-colheita.

Durante os 12 dias de armazenamento a perda de massa fresca chegou a $14,11 \%$ no tratamento Impacto hidropônico e $14,09 \%$ no Magali campo (Tabela 5). Os menores valores foram obtidos nos tratamentos Paloma hidropônico (12,03\%) e Paloma

Tabela 3. Valores médios de pH e acidez titulável em pimentões Paloma Hidropônico (PH), Paloma Campo (PC), Impacto Hidropônico (IH) e Magali Campo (MC) armazenados em condição ambiente com temperatura de $21 \pm 2{ }^{\circ} \mathrm{C}$ e umidade relativa do ar de $70 \pm 5 \%$, por 12 dias.

\begin{tabular}{|c|c|c|c|c|c|c|c|c|}
\hline \multirow[t]{2}{*}{ Período (dias) } & \multicolumn{4}{|c|}{$\mathrm{pH}$} & \multicolumn{4}{|c|}{ Acidez titulável (g de ácido málico $100 \mathrm{~g}^{-1}$ de produto) } \\
\hline & $\mathrm{PH}$ & $\mathrm{PC}$ & $\mathrm{IH}$ & $\mathrm{MC}$ & $\mathrm{PH}$ & $\mathrm{PC}$ & $\mathrm{IH}$ & $\mathrm{MC}$ \\
\hline 0 & $5,39^{\mathrm{Ab}}$ & $5,50^{\text {Aab }}$ & $5,51^{\text {Aab }}$ & $5,79^{\mathrm{Aa}}$ & $0,07^{\mathrm{Ab}}$ & $0,07^{\mathrm{Ab}}$ & $0,10^{\mathrm{ABab}}$ & $0,12^{\mathrm{BCa}}$ \\
\hline 3 & $5,25^{\mathrm{Ab}}$ & $5,48^{\text {Aab }}$ & $5,64^{\mathrm{Aa}}$ & $5,71^{\mathrm{ABa}}$ & $0,09^{\mathrm{Aa}}$ & $0,08^{\mathrm{Aa}}$ & $0,08^{\mathrm{Ba}}$ & $0,08^{\mathrm{Ca}}$ \\
\hline 8 & $5,58^{\mathrm{Aa}}$ & $5,50^{\mathrm{Aa}}$ & $5,36^{\mathrm{ABa}}$ & $5,43^{\mathrm{BCa}}$ & $0,07^{\mathrm{Ab}}$ & $0,07^{\mathrm{Aab}}$ & $0,11^{\mathrm{ABa}}$ & $0,11^{\mathrm{Ca}}$ \\
\hline 10 & $5,33^{\mathrm{Aa}}$ & $5,25^{\mathrm{Aa}}$ & $5,12^{\mathrm{Ba}}$ & $5,15^{\mathrm{Ca}}$ & $0,09^{\mathrm{Abc}}$ & $0,09^{\mathrm{Ac}}$ & $0,13^{\mathrm{Aab}}$ & $0,16^{\mathrm{Aa}}$ \\
\hline
\end{tabular}

Médias seguidas por letras maiúsculas distintas na coluna e minúsculas na linha diferem entre si a $1 \%$ pelo teste de Tukey.

Tabela 4. Valores médios de sólidos solúveis e vitamina C em pimentões Paloma Hidropônico (PH), Paloma Campo (PC), Impacto Hidropônico (IH) e Magali Campo (MC) armazenados em condição ambiente com temperatura de $21 \pm 2{ }^{\circ} \mathrm{C}$ e umidade relativa do ar de $70 \pm 5 \%$, por 12 dias.

\begin{tabular}{|c|c|c|c|c|c|c|c|c|}
\hline \multirow[t]{2}{*}{ Período (dias) } & \multicolumn{4}{|c|}{ Sólidos solúveis ( $\left.{ }^{\circ} \mathrm{Brix}\right)$} & \multicolumn{4}{|c|}{ Vitamina C (mg de ácido ascórbico $100 \mathrm{~g}^{-1}$ de produto) } \\
\hline & $\mathrm{PH}$ & $\mathrm{PC}$ & $\mathrm{IH}$ & $\mathrm{MC}$ & $\mathrm{PH}$ & $\mathrm{PC}$ & $\mathrm{IH}$ & $\mathrm{MC}$ \\
\hline 0 & $4,70^{\mathrm{Ac}}$ & $6,10^{\mathrm{Ab}}$ & $5,40^{\mathrm{Abc}}$ & $7,40^{\mathrm{Aa}}$ & $208,82^{\mathrm{ABa}}$ & $186,47^{\mathrm{Ab}}$ & $200,59^{\mathrm{Aab}}$ & $74,70^{\mathrm{Ac}}$ \\
\hline 3 & $5,10^{\mathrm{Ab}}$ & $5,70^{\mathrm{Aab}}$ & $5,10^{\mathrm{Ab}}$ & $6,30^{\mathrm{Ba}}$ & $194,12^{\mathrm{ABCa}}$ & $186,47^{\mathrm{Aa}}$ & $156,46^{\mathrm{Cb}}$ & $94,11^{\mathrm{Ac}}$ \\
\hline 8 & $5,20^{\mathrm{Aa}}$ & $5,30^{\mathrm{Aa}}$ & $5,20^{\mathrm{Aa}}$ & $5,30^{\mathrm{Ca}}$ & $178,24^{\mathrm{Cb}}$ & $188,24^{\mathrm{Aab}}$ & $206,47^{\mathrm{Aa}}$ & $76,64^{\mathrm{Ac}}$ \\
\hline 10 & $4,60^{\mathrm{Ac}}$ & $5,40^{\mathrm{Ab}}$ & $5,50^{\mathrm{Ab}}$ & $7,30^{\mathrm{Aa}}$ & $213,52^{\mathrm{Aa}}$ & $203,53^{\mathrm{Aa}}$ & $194,12^{\mathrm{Aa}}$ & $73,64^{\mathrm{Ab}}$ \\
\hline
\end{tabular}

Médias seguidas por letras maiúsculas distintas na coluna e minúsculas na linha diferem entre si a 1\% pelo teste de Tukey. 
Tabela 5. Valores médios de perda de massa fresca e umidade em pimentões Paloma Hidropônico (PH), Paloma Campo (PC), Impacto Hidropônico (IH) e Magali Campo (MC) armazenados em condição ambiente com temperatura de $21 \pm 2{ }^{\circ} \mathrm{C}$ e umidade relativa do ar de $70 \pm 5 \%$, por 12 dias.

\begin{tabular}{|c|c|c|c|c|c|c|c|c|}
\hline \multirow[t]{2}{*}{ Período (dias) } & \multicolumn{4}{|c|}{ Perda de massa fresca (\%) } & \multicolumn{4}{|c|}{ Umidade (\%) } \\
\hline & $\mathrm{PH}$ & $\mathrm{PC}$ & $\mathrm{IH}$ & $\mathrm{MC}$ & $\mathrm{PH}$ & PC & $\mathrm{IH}$ & $\mathrm{MC}$ \\
\hline 0 & 0,00 & 0,00 & 0,00 & 0,00 & $93,74^{\mathrm{Aa}}$ & $93,14^{\mathrm{Aa}}$ & $93,35^{\text {Aa }}$ & $92,19^{\mathrm{Aa}}$ \\
\hline 3 & $2,49^{\mathrm{A}}$ & $2,44^{\mathrm{A}}$ & $3,03^{\mathrm{A}}$ & $2,81^{\mathrm{A}}$ & $93,44^{\mathrm{Aa}}$ & $92,54^{\mathrm{Aa}}$ & $93,37^{\text {Аа }}$ & $90,48^{\mathrm{Aa}}$ \\
\hline 8 & $7,81^{\mathrm{A}}$ & $7,97^{\mathrm{A}}$ & $9,10^{\mathrm{A}}$ & $9,01^{\mathrm{A}}$ & $93,60^{\mathrm{Aa}}$ & $92,66^{\mathrm{Aa}}$ & $93,41^{\mathrm{Aa}}$ & $90,56^{\mathrm{Aa}}$ \\
\hline 10 & $10,09^{\mathrm{A}}$ & $10,27^{\mathrm{A}}$ & $11,82^{\mathrm{A}}$ & $11,73^{\mathrm{A}}$ & $93,52^{\text {Aa }}$ & $92,26^{\mathrm{Aa}}$ & $93,45^{\text {Aa }}$ & $94,62^{\mathrm{Aa}}$ \\
\hline
\end{tabular}

Médias seguidas por letras maiúsculas distintas na coluna e minúsculas na linha diferem entre si a 1\% pelo teste de Tukey.

campo (12,20\%), demonstrando ser uma cultivar menos susceptível à perda de massa fresca. A perda de massa resultou em murchamento dos frutos em todos os tratamentos, constatandose a partir de observação visual, provavelmente, diminuindo o potencial de comercialização dos mesmos. A perda de massa fresca em todos os tratamentos, no mesmo período de análise, foi inferior à obtida por Hojo et al. (2007), que observaram redução de 9,56\% aos 8 dias de armazenamento em pimentões da cultivar Ikeda mantidos à temperatura de $22 \pm 1{ }^{\circ} \mathrm{C}$ e umidade relativa entre 70 e $98 \%$. Vicentini et al. (1999) também obtiveram valores superiores após 10 dias de armazenamento de pimentões da cultivar Magali sob condição ambiente, em temperatura entre 20,2 e $21,8^{\circ} \mathrm{C}$, chegando a $23,74 \%$ de perda de massa fresca. Barros et al. (1994) observaram valores ainda maiores em frutos da cultivar Agronômico 10, mantidos em temperatura entre 18 e $30{ }^{\circ} \mathrm{C}$, atingindo $69,90 \%$ aos 30 dias de armazenamento. Díaz-Pérez et al. (2007) obtiveram valores inferiores aos obtidos nesse trabalho, chegando a 4,5\% de perda de peso em pimentões da cultivar Camelot após oito dias de armazenamento a $20^{\circ} \mathrm{C}$.

De acordo com Carmo (2004) os pimentões se tornam flácidos e murchos em poucos dias, quando mantidos em atmosfera com menos de $90 \%$ de umidade relativa. Para Medina (1984) os pimentões podem perder cerca de $6,10 \%$ de massa fresca sem apresentarem sintomas de murcha, mas com 10,20\% apresentam sintomas moderados e com 13,70\% sintomas severos, impossibilitando-os para o comércio. Já para Bussel e Kenisgberger (1975) a perda de massa aceitável para a comercialização não pode ser superior a $15 \%$. A porcentagem de perda de massa obtida nesse experimento (em média 13,10\%) encontra-se no limite superior para a conservação da qualidade do produto. Produtos armazenados resultam em perda de massa e, conseqüentemente, de qualidade, principalmente pelas alterações na textura, provocando o murchamento ou enrugamento (VICENTINI; CEREDA; CÂMARA, 1999). O murchamento pode ser retardado pela redução da taxa de transpiração a partir do aumento da umidade relativa do ar, diminuição da temperatura, redução do movimento do ar e uso de embalagens protetoras (BARROS; GOES; MINAMI, 1994). A perda de massa fresca deve ser evitada, pois a maioria dos produtos vegetais, inclusive o pimentão, é comercializada por peso, resultando em perdas econômicas tanto para o produtor como para o comerciante. De acordo com Goodwin e Mercer (1972), o processo de amadurecimento do fruto resulta em mudanças na permeabilidade das membranas celulares, tornando-as mais sensíveis à perda de água.

Não ocorreu variação significativa na umidade dos pimentões submetidos aos diferentes tratamentos e períodos de análise. Os valores de umidade oscilaram entre 89,40 e 94,62\% durante os 12 dias de armazenamento (Tabela 5), representando uma faixa mais ampla que a observada (90 e 92\%) por Antoniali et al. (2007) para o pimentão amarelo Zarco HS em função do grau de amadurecimento ( 0 a $100 \%$ da cor amarela). Pilon et al. (2006) observaram valores entre 94,10 e $94,50 \%$ para o pimentão verde da cultivar Magali. Os autores também relataram que conforme o pimentão vai atingindo o máximo de amadurecimento, o teor de umidade tende a diminuir, devido a mudanças na permeabilidade das membranas celulares, tornando-as mais sensíveis à perda de água, sendo que a mudança de umidade é influenciada pelo grau de amadurecimento. Assim, pimentões completamente amadurecidos podem apresentar teor de umidade significativamente menor que o total ou parcialmente verde, o que não ocorreu nesse experimento. Para Teixeira Neto (1997) a diminuição na umidade do produto armazenado é maior em temperaturas mais elevadas e pode ser explicada com base na transferência de massa do alimento para a atmosfera que o envolve, que depende do teor de umidade, da composição do alimento, da temperatura e da umidade relativa do ar.

\section{Conclusões}

As cultivares Paloma produzida em campo e Impacto produzida em hidroponia apresentaram a maior massa, sendo recomendadas para o cultivo, pois este produto é comercializado por peso.

A composição centesimal apresentou-se em concentrações aceitáveis para todos os tratamentos, com maior teor de umidade e menor de fibra bruta na cultivar Paloma, e maior teor de proteínas e carboidratos na cultivar Magali.

Os sólidos solúveis foram mais elevados no tratamento Magali campo. A umidade não foi influenciada pelos tratamentos e armazenamento. De maneira geral o teor de vitamina $\mathrm{C}$ foi maior no tratamento Impacto hidropônico e menor no Magali campo, ocorrendo variação no cultivo hidropônico. No entanto, aos 12 dias de armazenamento todos os tratamentos apresentaram valores elevados de vitamina $\mathrm{C}$. 
A perda de massa fresca atingiu $14,11 \%$ aos 12 dias de armazenamento, sendo considerado o período limite para o armazenamento de pimentão nessas condições.

As cultivares Paloma e Impacto podem ser recomendadas para o cultivo, não sendo necessário o cultivo da Paloma em sistema hidropônico, havendo a necessidade de avaliação da produção da cultivar Impacto em campo.

\section{Agradecimentos}

Ao Engenheiro Agrônomo Eduardo Xavier Nunes da empresa Xavier \& Baliza Ltda. e ao Sr. Valdivino Cândido de Jesus, pelo fornecimento das amostras de pimentão.

\section{Referências bibliográficas}

ANTONIALI, S. et al. Physico-chemical characterization of 'zarco hs' yellow bell pepper for different ripeness stages. Scientia Agricola, v. 64, n. 1, p. 19-22, 2007.

BARROS, J. C.; GOES, A.; MINAMI, K. Condições de conservação pós-colheita de frutos de pimentão (Capsicum annuum L.). Scientia Agricola, v. 51, n. 2, p. 363-368, 1994.

BLAT-MARCHIZELI, S. F. B.; YAÑEZ, L. D. T.; COSTA, C. P. P. Deu oídio. Revista Cultivar Hortaliças e Frutas, v. 4, n. 21, p. 10-11, 2003.

BUSSEL, J.; KENIGSBERGER, Z. Packaging green bell peppers in selected permeability films. Journal of Food Science, v. 40, n. 6, p. 1300-1303, 1975.

CARMO, S. A. Conservação pós-colheita de pimentão amarelo “Zarco HS”. Campinas, 2004. 127p. Tese - (Doutorado em Tecnologia Pós-colheita), Faculdade de Engenharia Agrícola, Universidade Estadual de Campinas - UNICAMP.

CASTELLANE, P. D.; ARAUJO, J. A. C. Cultivo sem solo - hidroponia. 1 ed. Jaboticabal: FUNEP, 1995.

CEASA/Goiás - Centrais de Abastecimento de Goiás S/A. Acompanhamento conjuntural da comercialização. Disponível em: <http://www.ceasagoias.gov.br> Acesso em: 23 jan. 2007.

CHEFTEL, J. C.; CHEFTEL. H.; BESANCON, P. Introdución a la bioquimica de los alimentos. 2 ed. Zaragosa: Acribia, 1983.

CHITARRA, M. I. F. Fisiologia e qualidade de produtos vegetais. In: BORÉM F.M. (Ed.). Armazenamento e processamento de produtos agrícolas. In: CONGRESSO BRASILEIRO DE ENGENHARIA AGRÍCOLA, 27. Anais... Poços de Caldas: SBEA, p. 1-58, 1998.

COCHRAN, H. L. Changes in $\mathrm{pH}$ of the pimiento during maturation. Proceeding of the American Society for Horticultural Science, v. 84, p. $409-411,1964$.

DÍAZ-PÉREZ, J. C.; MUY-RANGEL, M. D.; MASCORRO, A. G. Fruit size and stage of ripeness affect postharvest water loss in bell pepper fruit (Capsicum annuum L.). Journal of the Science of Food and Agriculture, Georgia, v. 87, n. 1, p. 68-73, 2007.
ESTAT. Sistema para análises estatísticas. Pólo Computacional/ Departamento de Ciências Exatas. Jaboticabal: Universidade Estadual Paulista, Faculdade de Ciências Agrárias e Veterinárias, 1994.

FRANCO, G. Tabela de composição química dos alimentos. 9 ed. São Paulo: Atheneu, 1999.

GOODWIN, T. W.; MERCER E. I. Introduction to plant biochemistry. 1 ed. Oxford: Pergamon, 1972.

GOULD, W. A. Tomato production, processing and quality evaluation. 1 ed. Westport: The AVI, 1974.

GRIERSON, D.; KADER, A. A. Fruit ripening and quality. In: ATHERTON, J.G.; RUDICH, J. (eds). The tomato crop: a scientific basis for improvement. London: Chapman Hall, 1986. n. 32, p. 241-280.

HOJO, E. T. D. et al. Uso de películas de fécula de mandioca e pvc na conservação pós-colheita de pimentão. Ciência e Agrotecnologia, v. 31, n. 1, p. 184-190, 2007.

INSTITUTO ADOLFO LUTZ. Normas Analíticas do Instituto Adolfo Lutz: métodos químicos e físicos para análise de alimentos. $2 \mathrm{ed}$. São Paulo: Instituto Adolfo Lutz, 1985.

LEE, S. K.; KADER, A. A. Preharvest and postharvest factors influencing vitamin $\mathrm{C}$ content of horticultural crops. Postharvest Biology and Technology, v. 20, n. 3, p. 207-220, 2000.

MEDINA, P. V. L. Manejo pós-colheita de pimentões e pimentas. Informe Agropecuário, v. 10, n. 113, p. 72-76, 1984.

NEPA. NÚCLEO DE ESTUDOS E PESQUISAS EM ALIMENTAÇÃO. Tabela Brasileira de Composição de Alimentos. Campinas: NEPAUNICAMP, 2004.

PILON, L. et al. Shelf life of minimally processed carrot and green pepper. Ciência Tecnologia de Alimentos, v. 26, n. 1, p. 150-158, 2006.

REIFSCHNEIDER, F. J. B. (Ed.). Capsicum: pimentas e pimentões no Brasil. Brasília: Embrapa Comunicação para Transferência de Tecnologia; Embrapa Hortaliças, 2000.

ROCHA, M. C. et al. Características de frutos de pimentão pulverizados com produtos de ação bactericida. Horticultura Brasileira, v. 24, n. 2, p. 185-189, 2006.

TEIXEIRA NETO, R. O. Atividade de água e transformação dos alimentos. In: ATIVIDADE DE ÁGUA EM ALIMENTOS. JARDIM, D. C. P.; GERMER, S. P. M. (Ed.). Campinas: ITAL, 1997. p. 2-1 a 2-9.

VICENTINI, N. M.; CEREDA, M. P.; CÂMARA, F. L. A. Revestimento de fécula de mandioca, perda de massa e alteração de cor de frutos de pimentão. Scientia Agrícola, v. 56, n. 3, p. 713-716, 1999.

VICENTINI, N. M.; CASTRO, T. M. R.; CEREDA, M. P. Influência de películas de fécula de mandioca na qualidade pós-colheita de frutos de pimentão (Capsicum annuum L.). Ciência e Tecnologia de Alimentos, v. 19, n. 1, p. 127-130, 1999.

VILlELA JÚNIOR, L. E. V.; ARAÚJO, J. A. C.; FACTOR, T. L. Comportamento do meloeiro em cultivo sem solo com a utilização de biofertilizante. Horticultura Brasileira, v. 21, n. 2, p. 153-157, 2003. 